\title{
Cloning of the Gene Encoding a Novel Lantibiotic Nukacin ISK-1, of Staphylococcus warneri
}

\section{Sashihara, Toshihiro}

Laboratory of Microbial Technology, Division of Microbial Science and Technology, Department of Bioscience and Biotechnology, Graduate School of Bioresource and Bioenvironmental Sciences, Kyushu University

\section{Kimura, Hirokazu}

Laboratory of Microbial Technology, Division of Microbial Science and Technology, Department of Bioscience and Biotechnology, Graduate School of Bioresource and Bioenvironmental Sciences, Kyushu University

Higuchi, Toshimasa

Laboratory of Microbial Technology, Division of Microbial Science and Technology, Department of Bioscience and Biotechnology, Graduate School of Bioresource and Bioenvironmental Sciences, Kyushu University

\section{Adachi, Asaho}

Laboratory of Microbial Technology, Division of Microbial Science and Technology, Department of Bioscience and Biotechnology, Graduate School of Bioresource and Bioenvironmental Sciences, Kyushu University

他

https://doi.org/10.5109/24365

出版情報: 九州大学大学院農学研究院紀要. 45 (1)，pp. 149-161，2000-11. Kyushu University バージョン：

権利関係 : 


\title{
Cloning of the Gene Encoding a Novel Lantibiotic, Nukacin ISK-1, of Staphylococcus warneri
}

\section{Toshihiro Sashihara*, Hirokazu Kimura*, Toshimasa Higuchi*, Asaho Adachi*, Hiromi Matsusaki*, Kenji Sonomoto and Ayaaki Ishizaki**}

\author{
Laboratory of Microbial Technology, Division of Microbial Science and Technology, Department of \\ Bioscience and Biotechnology, Faculty of Agriculture, \\ Kyushu University, Fukuoka 812-8581 \\ (Received June 21, 2000 and accepted August 18, 2000)
}

\begin{abstract}
Staphylococcus wameri ISK-1, we had reported as Pediococcus sp. ISK-1 previously, produces a novel bacteriocin, nukacin ISK-1. Edman degradation of the chemically reduced nukacin ISK-1 revealed a sequence of 27 amino acids, 7 of which were unidentified. Using single-specific-primer-PCR (SSP-PCR) product as a probe, a 3.6 -kb HindIII fragment containing nukacin ISK-1 structural gene $(n u k A)$ was cloned and sequenced. The deduced amino acid sequence of nukacin ISK-1 revealed that it was comprised of 57-amino acids, including a 30-amino acid leader region. The propeptide sequence showed significant similarity to those of lacticin-481 type lantibiotics. It was expected that an active 27-residue nukacin ISK-1 contained two lanthionines, one 3-methyllanthionine, and one dehydrobutyrine. . In the region upstream of $n u k A$, a part of long open reading frame (ORF), designated as $n u k M$, encoding a putative modification enzyme involved in the lantibiotic biosynthesis, was oriented in the opposite direction. In the region of downstream of $n u k A$, ORF1 was found, in which the sequence of the putative translational product was similar to those of response regulatory proteins such as LytT of Bacillus subtilis and VirR of Clostridium perfringens.
\end{abstract}

\section{INTRODUCTION}

Some microorganisms produce proteinaceous antimicrobial substances called bacteriocins. Bacteriocins are generally a heterogeneous group of bactericidal proteins which are effective against species that are closely related to the producer strains. Some bacteriocins inhibit the growth of food-borne pathogenic bacteria such as Listeria and Clostridium, which makes them potential as natural food preservatives in the near future.

Nisin, the antimicrobial peptide produced by Lactococcus lactis, was discovered in 1928 (Rogers and Whittier, 1928) and many lantibiotics have been reported (Jung, 1991). Lantibiotics are class I bacteriocins which contain unusual amino acids such as dehydroalanine (Dha), dehydrobutyrine (Dhb), lanthionine, and 3-methyllanthionine (Sahl et al., 1995). Lantibiotics are ribosomally synthesized as precursor peptides, which are post-translationally converted to the biologically active peptides through enzymatic modifications. First, serine and threonine residues in the propeptide portion of the

\footnotetext{
* Laboratory of Microbial Technology, Division of Microbial Science and Technology, Department of Bioscience and Biotechnology, Graduate School of Bioresource and Bioenvironmental Sciences, Kyushu University

** Corresponding author (E-mail: ishizaki@agr.kyushu-u.ac.jp)
} 
precursor peptide are dehydrated to Dha and Dhb, respectively. The double bonds of some of the Dha and Dhb residues react with the thiol group of a neighboring cysteine residue to form the respective thioether rings of lanthionine and 3-methyllanthionine in an enzyme-mediated reaction. Finally, the active lantibiotics are released and secreted by proteolytic cleavage of the leader peptide (Kupke and Götz, 1996).

In addition to the thioether amino acids, some lantibiotics contain a variety of other modified amino acids, including lysino-alanine, 2-aminovinyl-D-cysteine, hydroxy-aspartic acid and D-alanine (Jung, 1991, Skaugen et al., 1994). It has been considered that they play an important role to maintain the structure and the antimicrobial activity of lantibiotics. They also confer the antiprotease and $\mathrm{pH}$ tolerances due to the conformation of the thioether rings in the peptides. Thus, the modification enzymes for lantibiotics are attractive for biotechnological applications like protein engineering.

On the basis of the ring structures of lantibiotics, Jung (1991) proposed that they were divided into two types. Type A comprises those that are more elongated screw-shaped, amphiphilic polypeptides. Their primary bactericidal action is exerted by the formation of pores and depolarization of the bacterial cytoplasmic membrane. Type B comprises more compact, globular, and almost neutral amphiphilic polypeptides. Type-B lantibiotics show not only bactericidal activities but also inhibition of enzymatic activities (angiotensin-I converting enzyme or phospholipase $A_{2}$ ) (Fredenhagen et al., 1990), inhibition of herpes simplex virus-1, and immune adjuvant (Naruse et al., 1989, Brötz et $a l ., 1997)$. Moreover, type-A lantibiotics are classified with regard to their ring structure and their leader peptide with a characteristic cleavage site into three subtypes; nisin, lacticin-481, and lactocin-S types. The nisin type lantibiotics such as nisin A (Gross and Morell, 1971), nisin Z (Mulders et al., 1991, Matsusaki et al., 1996), epidermin (Allgaier et al., 1986), Pep5 (Kellner et al., 1991), and subtilin (Gross et al., 1973) are the most widely investigated in terms of their mechanism of pore formation (Moll et al., 1996), their biosynthesis(Siezen et al., 1996), and the relationship between their structures and antibacterial activity (Moll et al., 1996). The commercial application of these lantibiotics has been expected, nisin A being used as a natural food preservative in many countries (Delves-Broughton et al., 1996). In the past decade other lantibiotics belonging to lacticin-481 type were also isolated and characterized. This subtype includes lacticin 481 (Piard et al., 1993), bacteriocin J46 (Huot et al., 1996), variacin (Pridmore et al., 1996), streptococcin A-FF22 (Hynes et al., 1993), streptococcin A-M49 (Hynes et al., 1994), mutacin II (Woodruff et al., 1998), butyrivibriocin OR79A (Kalmokoff et al., 1999), and salivaricin A (Ross et al., 1993). However, these lantibiotics have not been extensively characterized yet. They have been considered something different in the mechanism of biosynthesis judging from these gene clusters from those of nisin type lantibiotics (Siezen et al., 1996).

Staphylococcus warneri ISK-1 was isolated in our laboratory from well-aged Nukadoko, a bed of fermented rice bran. This strain, which had been reported as Pediococcus sp. ISK-1 previously, produces a bacteriocin, nukacin ISK-1 (Kimura et al., $1997,1998)$. We reported the purification, the amino acid composition and sequence analysis of nukacin ISK-1, indicating that it is a peptide with a molecular mass of $2.9 \mathrm{kDa}$ containing 3 molecules of lanthionine and/or 3-methyllanthionine. The $\mathrm{N}$-terminal 7 amino acid residues were also determined as $\mathrm{NH}_{2}-\mathrm{K}-\mathrm{K}-\mathrm{K}-\mathrm{S}-\mathrm{G}-\mathrm{V}-\mathrm{I}$ by Edman degra- 
dation, the sequence of which showed high similarities to those of lacticin-481 type lantibiotics (Kimura et al., 1998). However, we could not determine the primary structure of nukacin ISK-1 completely, because Edman degradation after 8 cycles was blocked due to the possible thioether bridges. Here, we report the amino acid sequence of the nukacin ISK-1 reduced by the treatment with alkaline mercaptoethanol and cloning of its structural gene. The results strongly suggest that nukacin ISK-1 is a novel lantibiotic belonging to lacticin-481 type. Other ORFs relating to nukacin ISK-1 biosynthesis are also described.

\section{MATERIALS AND METHODOS}

\section{Bacterial strains, media and plasmid}

Staphylococcus warneri ISK-1, which had been referred to as Pediococcus sp. ISK-1 (Kimura et al., 1997, 1998), producing nukacin ISK-1 was used in this study. This strain was grown in MRS medium (Oxoid, Hampshire, United Kingdom) at $37^{\circ} \mathrm{C}$. Escherichia coli JM109 was grown in LB medium (Sambrook et al., 1989) at $37^{\circ} \mathrm{C}$. When needed, $40 \mathrm{mg} / \mathrm{liter}$ ampicillin was added to medium.

A plasmid pUC18 (Toyobo, Osaka, Japan) was used for cloning of nukacin ISK-1 structural gene.

\section{Amino acid sequence analysis of the reduced nukacin ISK-1}

The chemical reduction of the purified nukacin ISK-1 was performed according to the method as described by Meyer et al. (1994). The reduced nukacin ISK-1 was further purified by high performance liquid chromatography (HPLC) under the condition described previously (Kimura et $a l ., 1998$ ), and the amino acid sequence was analyzed by Edman degradation with an automated gas-phase protein sequencer (PSQ1; Shimadzu, Kyoto, Japan) with an on-line LC6A HPLC system (Shimadzu).

\section{DNA manipulations}

Total genomic DNA of ISK-1 strain was isolated by a combination of the methods of Marmur (1961) and Berns and Thomas (1965), except that $0.1 \mathrm{mg} / \mathrm{ml}$ of $N$-acetylmuramidase (Seikagaku, Tokyo, Japan) was used for cell lysis instead of lysozyme. Isolation of plasmids, digestion of DNA with restriction endonucleases, and agarose gel electrophoresis were carried out by standard procedures (Sambrook et al., 1989) or as recommended by the manufacturers. The total DNA library of ISK-1 strain was constructed with pUC18 and completely digested genomic DNA using HindIII. The primers, or the cassette oligonucleotide (Takara, Tokyo, Japan) used for single-specific-primer-PCR (SSP-PCR) (Shyamala and Ames, 1993), are shown in Table 1. Prior to SSP-PCR, the total DNA of ISK-1 strain was completely digested with XbaI and the cassette at $X b a I$ site was ligated to the total DNA fragments. They were then used as templates for PCR, which was performed with primers C-1 and PI-7 using $L A$ Taq DNA polymerase (Takara), in the procedures outlined by the manufacturer, using the following conditions: denaturation at $94^{\circ} \mathrm{C}$ for $1 \mathrm{~min}$, annealing at $55^{\circ} \mathrm{C}$ for $1 \mathrm{~min}$, and elongation at $72^{\circ} \mathrm{C}$ for $2 \mathrm{~min}$, through 30 cycles. Elution of PCR products from $1.2 \%$ agarose gel was performed after gel electrophoresis by using the Geneclean II Kit (Bio 101, Vista, CA, 
Table 1. Sequence of oligonucleotides used in this study

\begin{tabular}{|c|c|c|}
\hline Names & Sequences & Notes \\
\hline PI-7 & 5-CA(A/G) $\mathrm{CA}(\mathrm{A} / \mathrm{C} / \mathrm{G} / \mathrm{T}) \mathrm{GT}(\mathrm{A} / \mathrm{G}) \mathrm{AA}(\mathrm{A} / \mathrm{G} / \mathrm{T}) \mathrm{AC}(\mathrm{A} / \mathrm{G}) \mathrm{AA}(\mathrm{C} / \mathrm{T})^{\top} \mathrm{TG}(\mathrm{A} / \mathrm{G}) \mathrm{AA}-3^{\prime}$ & $\begin{array}{l}\text { The synthetic oligonucleotide } \\
\text { corresponding to the putative } 3 \text { region } \\
\text { of nukacin ISK-1 structural gene }\end{array}$ \\
\hline $\mathrm{C}-1$ & 5-GTACATATTGTCGTTAGAACGCGTAATACGA-3' & $\begin{array}{l}\text { The primer corresponding to the cassette } \\
\text { oligomer }\end{array}$ \\
\hline Cassette & $\begin{array}{l}\text { 5-OH GTACATATTGTCGTTAGAACGCGTAATACGACTCACTATAGGGAGAT-3' } \\
\text { 3'-CATGTATAACAGCAATCTTGCGCATTATGCTGAGTGATATCCCTCTAGATC OH-5' }\end{array}$ & Cassette oligomer \\
\hline
\end{tabular}

The underlined letters indicate the sequence of $X b a I$ site.

USA). The amplified PCR fragments were ligated into a pUC18 derivative T-vector, which was prepared by digestion with $S m a I$ and the addition of a single T by Taq DNA polymerase. Transformation of $E$. coli was carried out by electroporation, as described by Dower et al. (1988). Cells were electroporated in a $0.2-\mathrm{cm}$ cuvette with a Gene Pulser apparatus (Bio-Rad, Hercules, CA, USA) set at $25 \mu \mathrm{F}, 200 \Omega$ and $2.5 \mathrm{kV}$. After electroporation, cells were grown in SOC medium (Sambrook et al., 1989) at $37^{\circ} \mathrm{C}$ for $1 \mathrm{~h}$, and then incubated in LB agar medium containing $40 \mathrm{mg} /$ liter ampicillin.

\section{Hybridization experiments}

Hybridization was carried out as described by Southern (1975) under a stringent condition $\left(68^{\circ} \mathrm{C}\right)$. Colonies on LB plates were transferred to Hybond- $\mathrm{N}^{+}$nylon membrane (Amersham, Buckinghamshire, United Kingdom). The DNA probe used was the 720-bp product obtained by PCR with primers $\mathrm{C}-1$ and PI-7. Preparation of digoxigenin-labeled probe and detection of hybridization signals on membranes were carried out with a DIG DNA Labeling and Detection Kit (Boehringer, Mannheim, Germany).

\section{Nucleotide sequence analysis}

DNA fragments to be sequenced were further subcloned into pUC18, and nested sets of deletion clones were generated by using double-stranded Nested Deletion Kit (Pharmacia Biotech, Uppsala, Sweden), and they were sequenced with an ALF express sequencer (Pharmacia Biotech). The sequencing reaction based on the method of Sanger et al. (1977) was performed with the Auto Sequencer Core Kit (Toyobo) according with the instructions of the manufacturer. The resulting nucleotide sequence was analyzed by SDC-GENETYX genetic information processing software (Software Development, Tokyo, Japan). Sequence similarity searches were performed with the BLAST (Basic Local Alignment Search Tool) program and the NCBI (National Center for Biotechnology Information) databases.

\section{Nucleotide sequence accession number}

The nucleotide sequence data determined here appear in the EMBL, GenBank, and DDBJ databases under accession no. AB034941. 


\section{RESULTS}

\section{Amino acid sequence analysis of the reduced nukacin ISK-1}

As described previously (Kimura et al., 1998), Edman degradation after 8 cycles was blocked due to possible thioether bridges. Therefore, nukacin ISK-1 was treated with alkaline mercaptoethanol and the sequence of 27 amino acids was determined as, $\mathrm{NH}_{2}-\mathrm{K}-\mathrm{K}-\mathrm{K}-\mathrm{S}-\mathrm{G}-\mathrm{V}-\mathrm{I}-\mathrm{P}-\mathrm{X}-\mathrm{V}-\mathrm{X}-\mathrm{H}-\mathrm{D}-\mathrm{X}-\mathrm{H}-\mathrm{M}-\mathrm{N}-\mathrm{X}-\mathrm{F}-\mathrm{Q}-\mathrm{F}-\mathrm{V}-\mathrm{F}-\mathrm{X}-\mathrm{X}-\mathrm{X}-\mathrm{S}-\mathrm{COOH}$. Here, $\mathrm{X}$ indicates unidentified amino acids, probably modified post-translationally. The amino acid sequence of the reduced nukacin ISK-1 revealed a sequence similarity to those of lacticin-481 type lantibiotics.

\section{Cloning of nukA from Staphylococcus warneri ISK-1}

At first, for cloning of the nukacin ISK-1 structural gene (nukA), several oligonucleotides were synthesized based on the $\mathrm{N}$-terminal 7 -amino acids sequence of nukacin ISK-1, and they were used as probes and primers for Southern hybridization and SSP-PCR, respectively. However, the attempts were not successful using the degenerated oligonucleotides. Hence, primer PI-7 was designed based on the expected $\mathrm{C}$-terminal sequence as $-\mathrm{F}-\mathrm{Q}-\mathrm{F}-\mathrm{V}-\mathrm{F}-\mathrm{T}-\mathrm{C}-\mathrm{C}-\mathrm{S}-\mathrm{COOH}$, because the $\mathrm{C}-$ terminal region of lacticin-481 type lantibiotics was highly conserved, $-\mathrm{F}-\mathrm{V}-\mathrm{F}-\mathrm{T}-\mathrm{C}-\mathrm{C}-\mathrm{S}-\mathrm{COOH}$. Then, SSP-PCR was performed with primers PI-7 and C-1, and cassette-ligated total DNA fragment of ISK-1 strain as template, resulting in successful amplification of a 720-bp product. Because of the lack of the phosphate of 5'-terminal of the cassette, the PCR product can not be amplified by $\mathrm{C}-1$ primer alone. This product was purified from agarose gel after electrophoresis and cloned into a pUC18 derivative T-vector, and then used as a template for DNA sequencing. The nucleotide sequence of the PCR product corresponded to an amino acid sequence of the reduced nukacin ISK-1. Furthermore, the 720-bp PCR product was used as a probe to isolate and characterize a full-length $n u k A$ clone from genomic DNA library of ISK-1 strain. Finally, pPUH4 containing a 3.6-kb HindIII fragment hybridized with the probe was isolated by colony hybridization.

\section{Nucleotide sequence of 3.6-kb HindIII fragment, nukA, nukM, and ORF1}

The complete nucleotide sequence of the cloned 3.6-kb HindIII fragment was determined in both strands. The restriction map of the cloned fragment and the nucleotide sequence were shown in Figs. 1 and 2, respectively. In the 3.6-kb HindIII fragment, 174-bp open reading frame (ORF) containing nukacin ISK-1 structural gene ( $n u k A$ ) was found at position 2123 to 2296. In this ORF, two possible ATG start codons were found at positions 2123 and 2141. From the comparison of lacticin-481 type lantibiotics, position 2141 seemed to be the start codon. However, at 10 nucleotides upstream of position 2123, a possible ribosomal binding site (GGAG) was found. Hence, the nukA gene was predicted to be translated from position 2123 . The deduced amino acid sequence corresponding to the $\mathrm{N}$-terminal sequence of nukacin ISK-1 was found to start at residue 31 of the predicted product of the nukA gene. Thus, it seems that nukacin ISK-1 is synthesized as a 57-amino acid precursor peptide that is cleaved between $\mathrm{Ala}^{-1}$ and $\mathrm{Lys}^{+1}$ to form a 27 -residue propeptide. The predicted propeptide sequence was in good agreement with the amino acid sequence obtained from the 


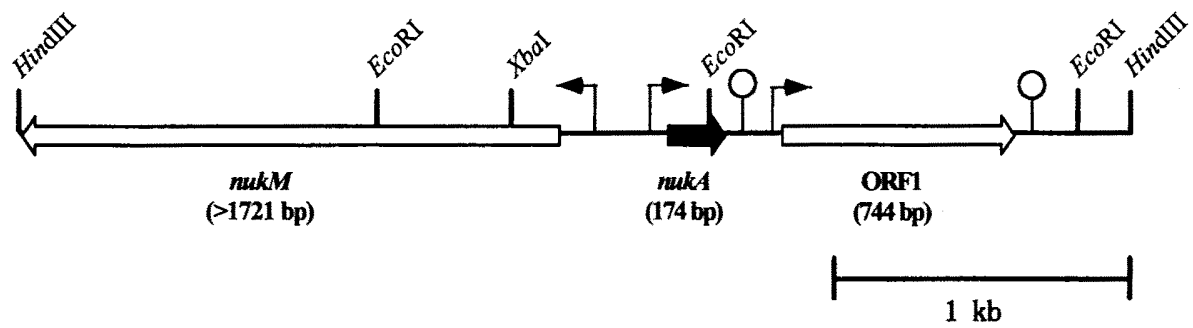

Fig. 1. Restriction map of the 3.6-kb HindIII fragment and organization of $n u k A$, nukM and ORF1. The arrows represent promoters. The possible $\rho$-independent transcription terminators for $n u k A$ and ORF1 are illustrated by lollipop-like symbols.

reduced nukacin ISK-1, except for unidentified amino acids.

In the region upstream of $n u k A$, a part of long ORF was found, designated as $n u k M$, in the opposite orientation (starting from position 1721). The translational product of this truncated gene was similar to that of the 5'-terminal region of lanM (Rince et al., 1994, Woodruff et al., 1998) encoding a modification enzyme involved in the biosynthesis of lantibiotics, (25-44\% identity for the N-terminal 572-amino acids). LanM is usually composed of more than 900 amino acids, suggesting that $n u k M$ contains a further $1-\mathrm{kb}$ of DNA.

An ORF1 (744-bp), which could encode a protein of 247 residues with a molecular mass of $28.8 \mathrm{kDa}$, was also found at 428 -bp downstream of $n u k A$, and the sequence of the putative translational product was similar to various response regulator proteins such as LytT of Bacillus subtilis (28\% identity, 48\% similarity) (Gothel et al., 1997) and VirR of Clostridium perfringens (23\% identity, 44\% similarity) (Shimizu et al., 1994). Therefore, the motif program Pfam, developed by Sonnhammer et al. (1997), was used to search ORF1 translational product for its defined amino acid sequence motif. The search revealed that 112 residues at the N-terminal region of ORF1 (residues 4 to 115) corresponded to the response regulator receiver domain.

Several -35 to -10 consensus sequences of $\sigma^{70}$-dependent promoters were found in the region between $n u k A$ gene and truncated $n u k M$ gene on both strands, and upstream of ORF1 (Fig. 2). Stem-loop structures were found downstream of $n u k A$ and ORF1. They might act as a $\rho$-independent transcription terminator sequences (calculated free energy of formation, $\Delta G_{0},-105.6$, and $123.2 \mathrm{~kJ} \cdot \mathrm{mol}^{-1}$, respectively) (Platt, 1986).

\section{Comparison of amino acid sequence of nukacin ISK-1 precursor peptide with those of lacticin-481 type lantibiotics}

The nukacin ISK-1 precursor peptide showed significant similarities to lacticin 481 (Piard et al., 1993), bacteriocin J46 (Huot et al., 1996), variacin (Pridmore et al., 1996), streptococcin A-FF22 (Hynes et al., 1993), streptococcin A-M49 (Hynes et al., 1994), mutacin II (Woodruff et al., 1998), butyrivibriocin OR79A (Kalmokoff et al., 1999) and salivaricin A (Ross et al., 1993) (Fig. 3). The position of the thioether bridge of these lacticin-481 type lantibiotics has not been determined yet except for lacticin 481 (Van 


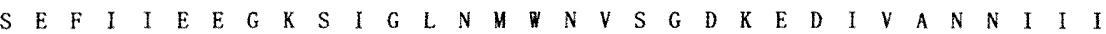

1 ITCGAAAGTTTATAATAAAGAAGAGGAAAACTATACGGATTTAAGTAGGTTAAATGTCTTGGTAGAAAAAGTAGATACTGACGTAATAATTAATATTACG HindIII

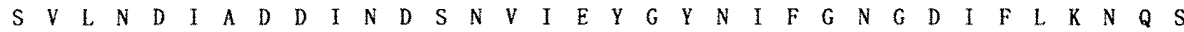
101 AATGATTTAACAGCTAACGTAGCAGTTATAACAGACTTAAATGATAAAGTATAGGTATTAAATATTTAGGTAATGGTAGTTATTTATTAAATAAAACTGA

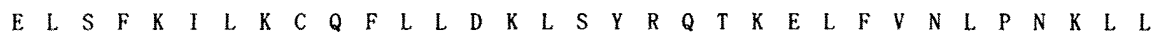
201 AAGATTACTTTTAAAATAATCAAATGTAACTTTTGTGTTTAGAAAGTTTCTTATAGAAACGCAAAAAAGATTTTTATGTAACTCACCCAAAAAGTTATTC

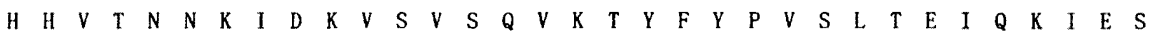

301 ACTACATGGCATAATAAAAATTATAGAAAATGGCTTTGTGAAACCTGGAATCATATTTTTATCCCATGACTTTCTCAAAGATAAACAAAATAAAGACTTA

$\begin{array}{lllllllllllllllllllllllllllllllllll}N & I & L & K & D & S & L & L & N & E & G & Y & E & E & L & K & N & F & L & S & K & R & K & N & A & Y & L & P & S & K & A & A & Q & I\end{array}$ 401 AATAATTGAATAGTGAATTATTTAAAAGTGGCATGAGAAGATCAAACAATTTGTTCGAGAAAGCGAATAAACGTATTTCTCCACTAAATCGTCGAACATA

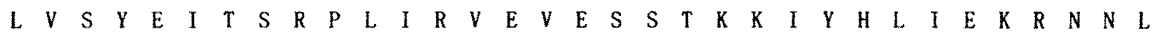
501 ATTATGACTCATGAGTTAACATGAAGAACCATTTTAAGAGTGAAGATGAAGACTACTGCAAAAGAAATATATTACATCATAAAGAAAAGATAACAATTCT

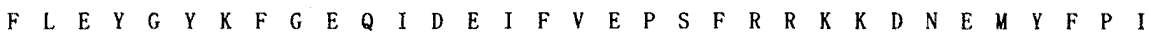

601 TTATTAAGCATTGGTATAAATTTCGGAGAACTTATAGAAGATATTTATGAAGCCCTCTTTTAGAGGAAAAAAATAGTAAAAGGTATATTTTACCCTATA

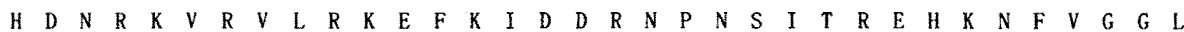

701 CTAGTAAAGAAAATTGAGAATGATTAGAGAAAAGCTTAAAATATAGTAGAGATAATCCTAATGAATATCAAGAAAGCACAAATAATTTATGAGGTGGATT

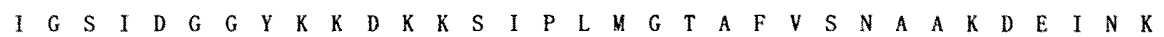

801 ATAAGGTGAATATAGAGGTGCCATAAAAAACAGAAAAAACCTATAGCCATTGTAAGGCCATCGCTTATGTCTTAATCGTCGAAATAGAAGATATAAGAAA

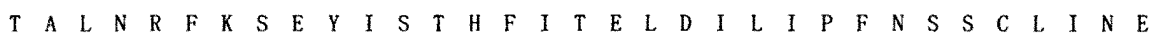

901 CATCGATTTAATGCTTTAAAACTAAGTATATACCTGCATACTTTATATCAAAGATTTAGTTAATTATAACCTTTTAATGACCTTGTGTCATATAAAAGCT

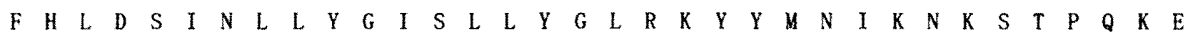
1001 TTACATTTAGTGAATATAAATTATTTATAGGATATCTGTTATTTATAGGGTTAGAAAACATTATGTATAAATAAAATAAAAATCTCCATCCAACGAAAAG

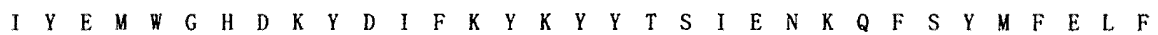
1101 ATATATAAGGTAGGTTGGCACCAGAAATATTAGATACTTAAATATGAATATCATACAACTATAAAGTAAAAAAACTTTTGACATGTATTTAAGATTCTTA

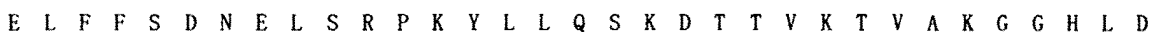

1201 AGATTTTTCTTTGATAGTAAAAGATTACTGGATCCAAATATATTATTAACTCTAAATAGTCACCAATGAAATCAGTGGCGAAATGGAGGTACATTTAGAG

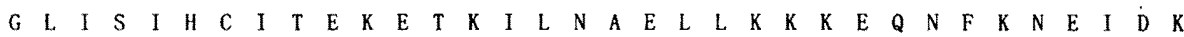
1301 GATTTTATGACTATACTGTTTAGCAAAGAAAAAGTCAAAAATAATTTAACCGAAGATTTTCAAAGAAAAAAAGAACTAACTTAAATAAAAGCTACAGAAA

$\begin{array}{llllllllllllllllllllllllllllllllll}\text { L } & F & S & F & Y & S & N & L & T & Q & E & L & D & N & \text { I } & \text { I } & S & P & Y & S & K & N & L & E & E & Y & I & I & G & K & E & C & L\end{array}$ 1401 GTTTTGCCTTTTATACTCAAATTTCAAACGAGATTTAGTAAATAATAACTACCTATTGAAAATAAATTGAGAAGTATATATTAGGGGAAAAGTGTATTA

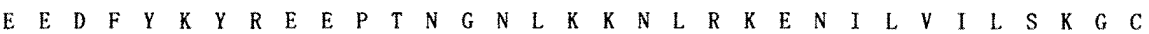

1501 AGAAGTAGTTTTATAAATATCGCAAGAAGTCCTCATAAAGGTAACTCAAAAAACAAATTAGAAAAAAGTAATTAATTTTGTTAGTTACTAAAAGGTGTTT

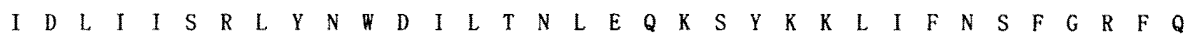
1601 ATAGATCTTATTATCTAGAATTCATCAAGGTTAGTTAATTACACAATTCAAGAACAAATCTCATAAAAAAATTTTATTTTAAACTTTTAGGAGATTTAAC nukM

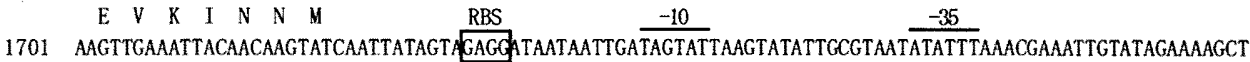
1701 TTCAACTTTAATGTTGTTCATAGTTAATATCATCTCCTATTATTAACTATCATAATTCATATAACGCATTATATAAATTTGCTTTAACATATCTTTTCGA 1801 GCAAACTTTAATCAAAACTACACATACTTGTAAGGAGAAAATGTCACAATATTTTTATTGATCGAACGATGTTAAAGCGAAATGAaGATTATAACCATTA 1801 CGTTTGAAATTAGTTTTGATGTGTATGAACATTCCTCTTTTACAGTGTTATAAAAATAACTAGCTTGCTACAATTTCGCTTTACTTCTAATATTGGTAAT 
1901 GATTGGAGTATGATGTTCTATTTAAAACGTCGTCTTTGCCTTTTTGGATTTTGATTGTTTTAACATTCAAAGTTTAAAAATAAAATAAGTATATCTTTTG 1901 CTAACCTCATACTACAAGATAAATTTTGCAGCAGAAACGGAAAAACCTAAAACTAACAAAATTGTAAGTTTCAAATTTTTATTTTATTCATATAGAAAAC

2001 GTGAAATAGTGAGATTTATATTTAAAATTAATATATTTATTCACCAAATATGTTAAAATGTGAAACATTTATAGTACACTATAATTTGAACATTGTTTAT 2001 CACTTTATCACTCTAAATATAAATTTTAATTATATAAATAAGTGGTTTATACAATTTTACACTTTGTAAATATCATGTGATATTAAACTTGTAACAAATA 2101 TrAaATT GGAGGTAACAAACATGGAAAATTCTAAAGTTATGAAGGACATTGAAGTAGCAAATTTATTAGAAGAGGTTCAAGAAGATGAATTGAATGAA RBS M E nukA $\longrightarrow$

2201 GTCTTAGGAGCTAAGAAAAAGTCAGGAGTAATCCCAACTGTGTCACACGATTGCCATATGAATTCTTTCCAATTTGTATTTACTTGTTGTTCATAAAAAG $V$ V L $G \begin{array}{lllllllllllllllllllllllllllll} & G & K & K & S & G & V & I & P & T & V & S & H & D & C & H & M & N & S & F & Q & F & V & F & T & C & C & S & *\end{array}$

2301 GGGAATGTTGTAAAATCAGTAAAAATAACTTTAAGTGATACTTACTTTAGTTTTTTTATTGATTAACATGATACTAATATTATGGCATGGCGAAAATCCG

2401 TAGTTTTGAAAAGAACTACGGATTTTTTATGAACCGTAAAACATATATAGTGTCTTTAGTTATTGTATTTTGGAGAGTATTGAAACCTTAATATTTTGTT 2501 CTTTCCAGCTTTTATTAAGATAACTTCATCGAAGGCAATTTATTGGCAACAATTACTTGAAGTCTAGCAGATATACTTTACAAAATAATCTTACAATCTA 2601 TCAATTTAAAAAMTTTTAAAGTTCATTTAATAATAATGATTTAAAAAAATAATTGTGATATATTAATGAAGTAAGCTTGGTTTTAATTTTTTATTGATA 2701 MGGAATGGGAAATTGATTTMTGAAAAAAATAAATGCTATTATTATAGACGATAATGCAAGTACTAGAGAGGATTTAAAAGTAAATCTATCTTACTTC $\begin{array}{llllllllllllllllllllllllllll}\text { RBS } & H & K & K & I & N & A & I & I & I & D & D & N & A & S & T & R & E & D & L & K & V & N & L & S & Y & F\end{array}$ ORF $\longrightarrow$

2801 TCATTTGTTTCATGTAAAGGTACATTTAGTGAATATATTGAGGCCAAAAATACCCTAGATAAGAAAGATATAGACTTAATATTTTTAAAAATAAATACAA $\begin{array}{llllllllllllllllllllllllllllllllll}S & F & V & S & C & K & G & T & F & S & E & Y & I & E & A & K & N & T & L & D & K & K & D & I & D & L & I & F & L & K & I & N & T & N\end{array}$

2901 ATAACAACAAGTTTATAGATATAGCCAATAATATCAATTCTATACATAAACATATTCAAATAGTTTTTCTATCTTCTGATTCCAAACACGCACATAMAAG $\begin{array}{llllllllllllllllllllllllllllllllll}N & N & K & F & I & D & I & A & N & N & I & N & S & I & H & K & H & I & Q & I & V & F & L & S & S & D & S & K & H & A & H & K & S\end{array}$

3001 TTTTGAAGCTCATCCTTTTGACTATTTAATACAACCAGTAGAGCCTATTAAATTGGAGAAGTGCTTACTTCATTTCAAAAATAGATGCAGAAAAAAATTC $\begin{array}{lllllllllllllllllllllllllllllllllll}F & E & A & H & P & F & D & Y & L & I & Q & P & V & E & P & I & K & L & F & K & C & L & L & H & F & K & N & R & C & R & K & K & F\end{array}$

3101 GATCTTAACARTCTTAAAAACAGAAAAATCGCCATTAAAAAGGGGAAATCTTTATATTTTTTAGAAATTGATAMAATTACAACAGCAGAATGTTGCGGTA $\begin{array}{llllllllllllllllllllllllllllllllll}D & L & N & N & L & K & N & R & K & I & A & I & K & K & G & K & S & L & Y & F & L & E & I & D & K & I & T & T & A & E & C & C & G & R\end{array}$

3201 GAAAAATAATTATCACTTTGGATGACAAAGAAACAGTTTCTTATAATGCCTCCTTAAAATATTTAGAAAAAAAACTCTATTCTTATGGATTTATTTTAGT $\begin{array}{llllllllllllllllllllllllllllllllll}K & I & I & I & T & L & D & D & K & E & T & V & S & Y & N & G & S & L & K & Y & L & E & K & K & L & Y & S & Y & G & F & I & L & V\end{array}$

3301 AAGTAGGTCATTACTTATTCCTTTAAAAAGTATTAAAAATATAATATTCGATAAGCATAGTAAATGCTATATTTTGAAATCGATTAAGAATAATACGGTT $\begin{array}{llllllllllllllllllllllllllllllllll}S & R & S & L & L & I & P & L & K & S & I & K & N & I & I & F & D & K & H & S & K & C & Y & I & L & K & S & I & K & N & N & T & V\end{array}$

3401 AAAATCACTCCAGAAAAGTATAAAAAAGTAAAGCAAACATTAAGTGAATTCAACTGGATTATTTAATCTGGTTCTATTACAAAAAATTAAAGTTTTAGAA $\begin{array}{llllllllllllllllllllll}K & I & T & P & E & K & Y & K & K & V & K & Q & T & L & S & E & F & N & \text { H } & \text { I } & \text { I } & *\end{array}$

3501 AATTCAGATATAACGTTATATTGTATTTTGAAAACAACTTATAATCTAGTTCCCCCATCTCCTTTACAAGAGATGGGGGGGGACATTTGATTTTTTGTT 3601 CAAAGTTTAAAGATAAAGCTT $\frac{\text { HindIII }}{3621}$

Fig. 2. Nucleotide sequence of the $3.6-\mathrm{kb}$ HindIII fragment containing the structural gene nukA, truncated nukM gene and ORF1, and the deduced amino acid sequences. The putative ribosome binding sequences are boxed and indicated by RBS. The putative transcriptional promoter sequences $(-35$ and -10$)$ are underlined. Termination codons are indicated by asterisks. The vertical arrow indicates cleavage site of the propeptide to form active nukacin ISK-1. The horizontal dashed arrows below the nucleotide sequence indicate putative transcriptional terminators. 


Nukacin ISK-1
Lacticin 481
Bacteriocin J46
Variacin
Streptococcin A-FF22
Streptococcin A-M49
Mutacin II
Butyrivibriocin OR79A
Salivaricin A

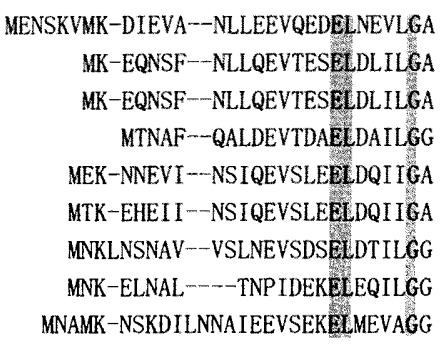

-KKKSGV IPTVSHDCHM NSFQFVTCCS -KGGSGVIHTISHECNM-NSWQFVFTCES -KGGSGVIHTISHEVIY ASWNFVFTCES ---GSGVIPTISHECHMNNSFQFVFTCES --GKNGVFKTISHECHL-NTWAFLATCCS --GKNGVFKTISHECHL-NTHAFLATECS NRWWQGVVPTVSYECRM-NSWQHVFTCE---GNGVIKTISHECHM-NTWQFIFTCCS -KRGSGWIATITDDCP-NS---VFVCC

\section{$\uparrow_{\text {Processing site }}$}

Fig. 3. Sequence comparison of the precursor of nukacin ISK-1 with those of lacticin-481 type lantibiotics. Identical residues are indicated in shaded boxes. The vertical arrow indicates processing site.

den Hooven et al., 1996). The thioether bridging pattern of lacticin-481 type lantibiotics has been considered to be the same structure, because the positions of serine, threonine and cysteine, which should be converted to unusual amino acids such as dehydro amino acids and lanthionine, are highly conserved (Fig. 3). The molecular mass of nukacin ISK-1 determined by fast atom bombardment mass spectrometry (FAB-MS) was 2,960 Da (Kimura et al., 1998). On the other hand, the calculated molecular mass of the propeptide portion of nukacin ISK-1 was 3,031 Da. Since nukacin ISK-1 contains 3 molecules of lanthionine and/or 3-methyllanthionine as described previously (Kimura et al., 1998), the location of the thioether bridges was predicted to be between residues 9 and 14,11 and 25, and 18 and 26 judging from the conserved residues. Threonine at residue 24 in the propeptide of nukacin ISK-1 could be converted to Dhb in the active form, because the residue could not be identified by amino acid sequence analysis of the reduced nukacin ISK-1 described above. In the case using this hypothesis, the calculated molecular mass of the active nukacin ISK-1 should be 2,959 Da, which was in good agreement with the molecular mass of that obtained by FAB-MS.

The proteolytic cleavage site of the leader peptide in the nukacin ISK-1 precursor peptide was not similar to the consensus sequence found in other type-A lantibiotics such as nisin and epidermin $\left(\mathrm{X}^{-4}-\mathrm{X}^{-3}-\mathrm{PrO}^{-2}-\mathrm{X}^{-1}-\mathrm{X}^{+1}\right.$, where residues $\mathrm{X}^{-4}, \mathrm{X}^{-2}$, and $\mathrm{X}^{+1}$ are hydrophobic, residue $\mathrm{X}^{-3}$ is negatively charged or polar, and residue $\mathrm{X}^{-1}$ is large and positively charged or polar) (Jung, 1991). The leader peptides of lacticin-481 type lantibiotics have a conserved negatively charged central part with several glutamic acid residues, and the cleavage site is characterized by $\mathrm{Gly}^{-2}-\mathrm{Ala} / \mathrm{Gly}^{-1}$ similar to that of non-lantibiotic bacteriocins of lactic acid bacteria (Klaenhammer, 1993) (Fig. 3).

\section{DISCUSSION}

Staphylococcus epidermidis produces some nisin type lantibiotics such as Pep5 (Kellner et al., 1991), epidermin (Allgaier et al., 1986), gallidermin (Schnell et al., 1989), 


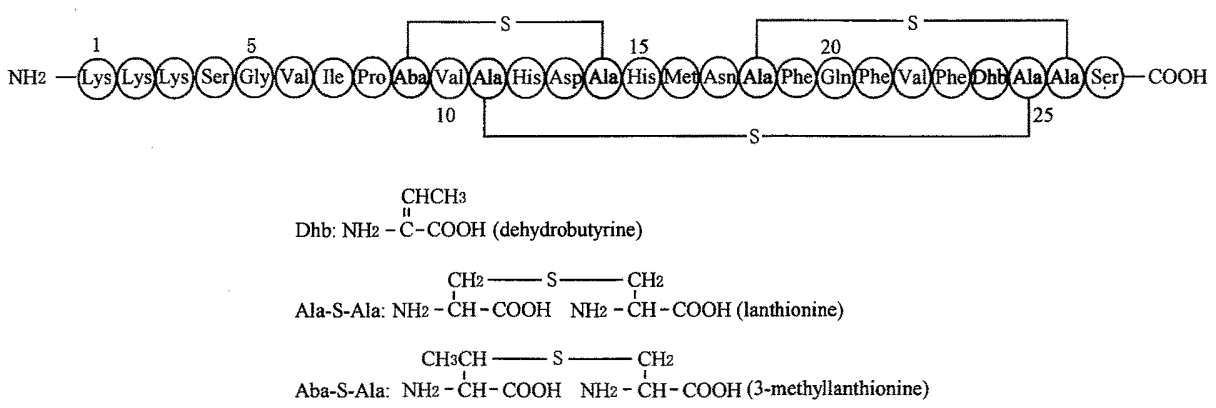

Fig. 4. Proposed structure of nukacin ISK-1. Ala-S-Ala, Aba-S-Ala, and Dhb indicate lanthionine, 3-methyllanthionine, and dehydrobutyrine, respectively.

and epilancin K7 (Van de Kamp et al., 1995). In this study, we demonstrated strong evidence that nukacin ISK-1 was a novel lacticin-481 type lantibiotic. This is the first report that staphylococci produce lacticin-481 type lantibiotics. Sequence analysis of 3.6-kb HindIII fragment showed that nukacin ISK-1 was synthesized as a 57-amino acid precursor peptide. The prepeptide sequence was very similar to those of lacticin-481 type lantibiotics. From the sequence similarity of lacticin-481 type lantibiotics, it was predicted that the secondary structure of nukacin ISK-1 was almost the same as that of lacticin 481. The calculated molecular mass of the active nukacin ISK-1 based on the aforementioned assumption was in good agreement with that measured by FAB-MS. In Fig. 4, we are proposing the structure of nukacin ISK-1.

In the region upstream of $n u k A$, a part of long ORF designated as $n u k M$, which encodes a putative modification enzyme involved in the lantibiotic biosynthesis, was oriented in the opposite direction. In the past a few years, many gene clusters of lacticin-481 type lantibiotics have been characterized (Rince et al., 1997, Chen et al., 1999, McLaughlin et al., 1999). The principal difference between the gene clusters found in lacticin-481 type lantibiotics and those of nisin type lantibiotics, is that the former gene clusters have no genes for proteins with a significant sequence similarity to LanB. LanB was elucidated as a dehydration enzyme in nisin type lantibiotics by in vivo experiment (Sen et al., 1999). However, the former gene clusters contain a similar gene (lanM) in size to the LanB protein genes. Furthermore, the C-terminal half of the translational product (LanM) has sequence similarity to the LanC proteins including the 7 conserved segments (Siezen et al., 1996). LanC seems to catalyze the formation of thioether rings between the dehydrated amino acids and cysteine residue. Although there is no obvious sequence similarity to the LanB proteins, it seems possible that LanM represents hybrid proteins, capable of catalyzing both of the reactions assumed for LanB and LanC. In biosynthesis of nisin and subtilin, it is revealed that post-translational modifications occur at a level of membrane-associated multimeric lanthionine synthetase complex (Siegers et al., 1996, Kiesau et al., 1997). Now, it is interesting to know how the multimeric lanthionine synthetase complex of lacticin-481 type lantibiotics is associated.

In the region downstream of $n u k A$, ORF1, having a high similarity to the response regulator gene, was located. As found in other lantibiotic gene clusters such as nisin, 
subtilin and epidermin, the transcription of some gene clusters involved in biosynthesis of lantibiotics are positively controlled by two-component regulatory system composed of response regulatory protein and histidine kinase, i.e. NisR and NisK in nisin (Kuipers et al., 1995), SpaR and SpaK in subutilin (Klein et al., 1993), and EpiQ in epidermin (Peschel et al., 1993). However, the deduced amino acid sequence of ORF1 had low similarities to these regulatory proteins belonging to nisin type lantibiotics $20.5 \%$ identity for 220 amino acids of NisR, 19.8\% identity for 81 amino acids of SpaR, and 19.5\% identity for 82 amino acids of EpiQ). NisR and SpaR have both response regulator receiver domain and transcriptional regulator domain in $\mathrm{N}$ - and $\mathrm{C}$-terminal regions, respectively. On the other hands, putative translational product of ORF1 has only a response regulator receiver domain in $\mathrm{N}$-terminal region. However, VirR of Clostridium perfringens, which shows high structural similarity to ORF1 translational product, still acts as a transcriptional regulator (Shimizu et al., 1994). Therefore, further investigation of nukacin ISK-1 gene clusters and further molecular analysis of biosynthetic genes are presently in progress.

\section{REFERENCES}

Allgaier, H., G. Jung., R. G. Werner, U. Schneider and H. Zähner 1986 Epidermin: sequencing of a heterodet tetracyclic 21-peptide amide antibiotic. Eur. J. Biochem., 160: 9-22

Berns, K. I. and C. A. Thomas JR. 1965 Isolation of high molecular weight DNA from Hemophilus influenzae. J. Mol. Biol., 11: 476-490

Brötz, H., G. Bierbaum, P. E. Reynolds and H.-G. Sahl 1997 The lantibiotic mersacidin inhibits peptidoglycan biosynthesis at the level of transglycosylation. Eur. J. Biochem., 246: 193-199

Chen, P., F. Qi, J. Novak and P. W. Caufield 1999 The specific genes for lantibiotic mutacin II biosynthesis in Streptococcus mutans T8 are clustered and can transferred en bloc. Appl. Environ. Microbiol., 65: 1356-1360

Delves-Broughton, J., P. Blackburn. R. J. Evans and J. Hugenholtz 1996 Applications of the bacteriocin, nisin. Antonie Leeuwenhoek, 69: 193-202

Dower, W. J., J. F. Miller and C. W. Ragsdale 1988 High efficiency transformation of Escherichia coli by high voltage electroporation. Nucleic Acids Res., 16: 6127-6145

Fredenhagen, A., G. Fendrich, F. Märki, W. Märki, J. Gruner, F. Raschdorf and H. H. Peter 1990 Duramycins B and C, two new lanthionine containing antibiotics as inhibitors of phospholipase $\mathrm{A}_{2} . \mathrm{J}$. Antibiot., 43: 1403-1412

Gothel, S. F., R. Schmid, A. Wipat, N. M. Carter, P. T. Emmerson, C. R. Harwood and M. A. Marahiel 1997 An internal FK506-binding domain is the catalytic core of the prolyl isomerase activity associated with the Bacillus subtilis trigger factor. Eur. J. Biochem., 244: 59-65

Gross, E. and J. L. Morell 1971 The structure of nisin. J. Am. Chem. Soc., 93: 4634-4635

Gross, E., H. H. Kiltz and E. Nebelin 1973 The structure of subtilin. Hoppe-Seyler's Z. Physiol. Chem., 354: $810-812$

Huot, E., J. Meghrous, C. Barrena-Gonzalez and H. Petitdemange 1996 Bacteriocin J46, a new bacteriocin produced by Lactococcus lactis subsp. cremoris J46: isolation and characterization of the protein and its gene. Anaerobe., 2: 137-145

Hynes, W. L., J. J. Ferretti and J. R. Tagg 1993 Cloning of the gene encoding streptococcin A-FF22, a novel antibiotic produced by Streptococcus pyogenes, and determination of its nucleotide sequence. Appl. Environ. Microbiol., 59: 1969-1971

Hynes, W. L., V. L. Friend, and J. J. Ferretti 1994 Duplication of the lantibiotic structural gene in M-type 49 group A Streptococcus strains producing streptococcin A-M49. Appl. Environ. Microbiol., 60: $4207-4209$

Jung, G. 1991 Lantibiotics: a survey. In "Nisin and novel lantibiotics", ed. by G. Jung and H.-G. Sahl, ESCOM Science Publishers B.V., Leiden, Netherlands, pp.1-34 
Kalmokoff, M. L., D. Lu, M. F. Whitford and R. M. Teather 1999 Evidence for production of a new lantibiotic (Butyrivibriocin OR79A) by the ruminal anaerobe Butyrivibrio fibrisolvens OR79A: characterization of the sutuctural gene encoding butyrivibriocin OR79A. Appl. Environ. Microbiol., 65: $2128-2135$

Kellner, R., G. Jung and H.-G. Sahl 1991 Structure elucidation of the tricyclic lantibiotic Pep5 containing eight positively charged amino acids. In "Nisin and novel lantibiotics", ed. by G. Jung and H.-G. Sahl, ESCOM Science Publishers B.V., Leiden, Netherlands, pp.141-158

Kiesau, P., U. Eikmanns, Z. Gutowski-Eckel, S. Weber, M. Hammelmann and K.-D. Entian 1997 Evidence for a multimeric subtilin synthetase complex. J. Bacteriol., 179: 1475-1484

Kimura, H, R. Nagano, H. Matsusaki, K. Sonomoto and A. Ishizaki 1997 A bacteriocin of strain Pediococcus sp. ISK-1 isolated from Nukadoko, bed of fermented rice bran. Biosci. Biotechnol. Biochem., 61: 1049-1051

Kimura, H., H. Matsusaki, T. Sashihara, K. Sonomoto and A. Ishizaki 1998 Purification and partial identification of bacteriocin ISK-1, a new lantibiotic produced by Pediococcus sp. ISK-1. Biosci. Biotechnol. Biochem., 62: 2341-2345

Klaenhammer, T. R. 1993 Genetics of bacteriocins produced by lactic acid bacteria. FEMS Microbiol. Rev., 12: $39-86$

Klein, C., C. Kaletta and K.-D. Entian 1993 Biosynthesis of the lantibiotic subtilin is regulated by a histidine kinase/response regulator system. Appl. Environ. Microbiol., 59: 296-303

Kuipers, O. P., M. M. Beerthuyzen, P. G. G. A. de Ruyter, E. J. Luesink and W. M. de Vos 1995 Autoregulation of nisin biosynthesis in Lactococcus lactis by signal transduction. J. Biol. Chem., 270: $27299-27304$

Kupke, T. and F. Götz 1996 Post-translational modifications of lantibiotics. Antonie Leeuwenhoek, 69 : $139-150$

Marmur, J. 1961 A procedure for the isolation of deoxyribonucleic acid from microorganisms. J. Mol Biol., 3: 208-218

Matsusaki, H., N. Endo, K. Sonomoto and A. Ishizaki 1996 Development of purification method and identification of a peptide antibiotic produced by Lactococcus lactis IO-1. Food Sci. Technol., Int., 2: $157-162$

McLaughlin R. E., J. J. Ferretti and W. L. Hynes 1999 Nucleotide sequence of the streptococcin A-FF22 lantibiotic regulon: model for production of the lantibiotic SA-FF22 by strains of Streptococcus pyogenes. FEMS Microbiol. Lett., 175: 171-177

Meyer, H. E., M. Heber, B. Eisermann, H. Korte, J. W. Metzger and G. Jung 1994 Sequence analysis of lantibiotics: chemical derivatization procedures allow a fast access to complete Edman degradation. Anal. Biochem, 223: 185-190

Moll, G. N., G. C. K. Roberts, W. N. Konings and A. J. M. Driessen 1996 Mechanism of lantibiotic-induced pore-formation. Antonie Leeuwenhoek, 69: 185-191

Mulders, J. W. M., I. J. Boerrigter, H. S. Rollema, R. J. Siezen and W. M. de Vos 1991 Identification and characterization of the lantibiotic nisin Z, a natural nisin variant. Eur. J. Biochem., 201: 581-584

Naruse, N., O. Tenmyo, K. Tomita, M. Konishi, T. Miyaki, H. Kawaguchi, K. Fukase, T. Wakamiya and T. Shiba 1989 Lanthiopeptin, a new peptide antibiotic: production, isolation and properties of lanthiopeptin. J. Antibiot., 42: 837-845

Peschel, A., J. Augustin, T. Kupke, S. Stevanovic and F. Götz 1993 Regulation of epidermin biosynthetic genes by EpiQ. Mol. Microbiol., 9: 31-39

Piard, J.-C., O. P. Kuipers, H. S. Rollema, M. J. Desmazeaud and W. M. de Vos 1993 Structure, organization, and expression of the lct gene for lacticin 481, a novel lantibiotic produced by Lactococcus lactis. J. Biol. Chem, 268: 16361-16368

Platt, T. 1986 Transcription termination and the regulation of gene expression. Ann. Rev. Biochem., 55: $339-372$

Pridmore, D., N. Rekhif, A.-C. Pittet, B. Suri and B. Mollet 1996 Variacin, a new lanthionine-containing bacteriocin produced by Micrococcus varians: comparison to lacticin 481 of Lactococcus lactis. Appl. Environ. Microbiol., 62: 1799-1802

Rince, A., A. Dufour, S. Le Pogam, D. Thuault, C. M. Bourgeois and J. P. Le Pennec 1994 Cloning, expression, and nucleotide sequence of genes involved in production of lactococcin DR, a bactioriocin from Lactococcus lactis subsp. lactis. Appl. Environ. Microbiol., 60: 1652-1657 
Rince, A., A. Dufour, P. Uguen, J.-P. Le Pennec and D. Haras 1997 Characterization of the lacticin 481 operon: the Lactococcus lactis genes $l c t F$, lctE, and $l c t G$ encode a putative ABC transporter involved in bacteriocin immunity. Appl. Environ. Microbiol., 63: 4252-4260

Rogers, L. A. and E. O. Whittier 1928 Limiting factors in the lactic fermentation. J. Bacteriol, 16: 211-229

Ross, K. F., C. W. Ronson and J. R. Tagg 1993 Isolation and characterization of the lantibiotic salivaricin A and its structural gene salA from Streptococcus salivarius 20P3. Appl. Environ. Microbiol., 59: $2014-2021$

Sahl, H.-G., R. W. Jack and G. Bierbaum 1995 Biosynthesis and biological activities of lantibiotics with unique post-translational modifications. Eur. J. Biochem., 230: 827-853

Sambrook, J., E. F. Fritsch and T. Maniatis 1989 Molecular cloning: a laboratory manual, 2nd ed. Cold Spring Harbor Laboratory Press, N. Y. (USA)

Sanger, F., S. Nicklen and A. R. Coulson 1977 DNA sequencing with chain-terminating inhibitors. Proc. Natl. Acad. Sci. USA, 74: 5463-5467

Schnell, N., K.-D. Entian, F. Götz, T. Hörner, R. Kellner and G. Jung 1989 Structural gene isolation and prepeptide sequence of gallidermin, a new lanthionine containing antibiotic. FEMS Microbiol. Lett., 58: $263-268$

Sen, A. K., A. Narbad, N. Horn, H. M. Dodd, A. J. Parr, I. Colquhoun and M. J. Gasson 1999 Post-translational modification of nisin: the involvement of NisB in the dehydration process. Eur. J. Biochem., 261: 524-532

Shimizu, T., W. Ba-Thein, M. Tamaki and H. Hayashi 1994 The virR gene, a member of a class of perfringolysin $\mathrm{O}$, collagenase, and hemagglutinin in Clostridium perfringens. J. Bacteriol, 176: 1616-1623

Shyamala, V., G. and F.--L. Ames 1993 Genome walking by single-specific-primer-polymerase chain reaction. Methods Enzymol., 217: 436-446

Siegers, K., S. Heinzmann and K.-D. Entian 1996 Biosynthesis of lantibiotic nisin. J. Biol. Chem., 271: 12294-12301

Siezen, R. J., O. P. Kuipers and W. M. de Vos 1996 Comparison of lantibiotic gene clusters and encoded proteins. Antonie Leeuwenhoek, 69: 171-184

Skaugen, M., J. Nissen-Meyer, G. Jung, S. Stevanovic., K. Sletten, C. I. M. Abildgaard and I. F. Nes 1994 In vivo conversion of $\mathrm{L}$-serine to $\mathrm{D}$-alanine in a ribosomally synthesized polypeptide. $J$. Biol. Chem., 269: $27183-27185$

Sonnhammer, E. L. L., S. R. Eddy and R. Durbin 1997 A comprehensive database of protein domain families based on seed alignments. Proteins, 28: $405-420$

Southern, E. M. 1975 Detection of specific sequence among DNA fragments separated by gel electrophoresis. J. Mol. Biol., 98: 503-517

Van de Kamp, M., H. W. van den Hooven, R. N. H. Konings, C. W. Hilbers, F. J. M. van de Ven, G. Bierbaum, H.-G. Sahl, O. P. Kuipers, R. J. Siezen and W. M. de Vos 1995 Elucidation of the primary structure of the lantibiotic epilancin K7 from Staphylococcus epidermidis K7. Cloning of the epilancin K7-encoding gene and NMR analysis of mature epilancin K7. Eur. J. Biochem., 230: 587-600

Van den Hooven, H. W. F. M. Lagerwerf, W. Heerma, J. Haverkamp, J.-C. Piard, C. W. Hibers, R. J. Siezen, O. P. Kuipers and H. S. Rollema 1996 The structure of the lantibiotic lacticin 481 produced by Lactococcus lactis: location of the thioether bridges. FEBS Lett., 391: 317-322

Woodruff, W. A., J. Novak and P. W. Caufield 1998 Sequence analysis of $m u t A$ and $m u t M$ genes involved in the biosynthesis of the lantibiotic mutacin II in Streptococcus mutans. Gene, 206: 37-43 